https://doi.org/10.30843/nzpp.2018.71.207

\title{
Validating outsourced high throughput automated qPCR for increased research outputs from forest pathology trials
}

Renelle O’Neill ${ }^{1, \star}$, Rebecca McDougal ${ }^{1}$, Stuart Fraser ${ }^{1}$, Catherine Banham ${ }^{1}$, Mike Cook ${ }^{2}$, Ana Claasen², Suzanne Simpson ${ }^{2}$ and Nari Williams ${ }^{1}$

${ }^{1}$ Scion, Private Bag 3020, Rotorua 3046, New Zealand

${ }^{2}$ Slipstream Automation, PO Box 1979, Palmerston North, New Zealand

${ }^{*}$ Corresponding author: renelle.oneill@scionresearch.com

Needle diseases of Pinus radiata caused by Phytophthora pluvialis and Phythophthora kernoviae have been increasingly recognised since the discovery of red needle cast in 2008. There is a need for rapid diagnostic screening of numerous samples, but sample processing time, equipment and staff availability limit the throughput and utilisation of diagnostic qPCR analysis in the research environment. Automated and high-throughput capable DNA extraction and real-time PCR provides the opportunity to expand the capacity of research trial analysis and a potential alternative to laborious isolation and plating but must be thoroughly validated before results can be used with confidence. The use of a high-throughput format for qPCR assays targeting Phytophthora pluvialis and Phythophthora kernoviae was validated on a robotic platform, proving to be consistently more sensitive than isolation, achieving qPCR detection down to $1 \%$ diluted inoculated material for Phytophthora kernoviae and 10\% for Phytophthora pluvialis. Plating results yielded a $60 \%$ detection rate of Phythophthora pluvialis in inoculated needle fragments, whereas qPCR yielded a 100\% detection on the same material. High throughout automated qPCR can, therefore, be utilised with confidence in forest pathology research trial analyses in future.

https://doi.org/10.30843/nzpp.2018.71.211

\section{Evaluation of different methods for isolating Phytophthora spp. from a Canterbury waterway}

\author{
Ashika Prasad*, Seona Casonato, Natalia Cripps-Guazzone and Eirian Jones \\ Lincoln University, PO Box 85084, Lincoln 7647, Canterbury, New Zealand \\ ${ }^{*}$ Corresponding author: Ashika.Prasad@lincolnuni.ac.nz
}

Phytophthora spp. pose a risk to New Zealand's managed and natural ecosystems. As Phytophthora spp. are well adapted to aquatic environments, water surveillance can be used to identify their distribution. Seven bait species (Rhododendron arborescens, Pittosporum undulatum, Banksia attenuata, Camellia japonica, Pittosporum eugenioides, Pinus radiata, and Cedrus deodara) were evaluated for Phytophthora spp. isolation. Water was collected from 2 sites in the Suckling river (Tai Tapu) and half was membranefiltered (3- $\mu \mathrm{m}$ pore size) to capture spores. Leaf baits were floated directly on unfiltered water at room temperature in the laboratory for 7 days. Baits were also placed in nylon-mesh bags and floated in the Suckling river sites (in situ) for 7 days. Leaf lesions and membrane filters were cultured on Phytophthora spp. selective media. Eighty-six Phytophthora spp. isolates representing 5 colony morphotypes were recovered, 6 ( 3 morphotypes) from membrane filters, 25 (4 morphotypes) from baits on collected river water, and 55 ( 5 morphotypes) from in situ baits. The highest numbers of isolates were recovered from $R$. arborescens (50.6\%; 4 morphotypes), Pinus radiata (17.2\%; 3 morphotypes) and Pittosporum undulatum (12.6\%; 2 morphotypes). In situ baiting using Rhododendron arborescens and Pinus radiata was the most effective method of isolating Phytophthora species. 